\title{
Landscape Performance and Fruiting of 12 Privet Selections Grown in Northern and Southern Florida
}

\author{
Sandra B. Wilson ${ }^{1,2,4}$, Gary W. Knox ${ }^{1,3}$, Keona L. Nolan ${ }^{1,2}$, \\ and James Aldrich ${ }^{1,3}$
}

AdDitional INDEX wORDs. chinese privet, cultivar trialing, glossy privet, invasive plants, japanese privet, Ligustrum japonicum, Ligustrum lucidum, Ligustrum sinense, seed germination, woody shrubs

Summary. Chinese privet (Ligustrum sinense) and glossy privet (L. lucidum) have been classified as Category I invasives in Florida. The closely related japanese privet (L. japonicum) has escaped cultivation but is not considered a problem species in Florida. Plant growth, visual quality, flowering, and fruiting were assessed for the resident species (wild-type form) and selected cultivars of chinese privet, glossy privet, and japanese privet planted in northern and southern Florida for 132 weeks. Visual quality varied by site, month, and cultivar. With the exception of 'Swift Creek' chinese privet (which did not survive in southern Florida), all cultivars survived the study. All plants fruited in northern Florida. In southern Florida, fruiting was less abundant and not observed for 'Jack Frost' japanese privet, 'Rotundifolium' japanese privet, 'Swift Creek' chinese privet, 'Suwannee River' hybrid privet, and glossy privet within 132 weeks. In northern and southern Florida, the growth index rate was lower for 'Lake Tresca' japanese privet, 'Rotundifolium' japanese privet, and 'Suwannee River' hybrid privet than other cultivars. There was a significant interaction between temperature and species for seed germination. Germination in incubators set with a 12-hour photoperiod ranged from $51 \%$ to $78.5 \%$ for chinese privet, japanese privet, and glossy privet among temperatures, with the exception of glossy privet at $35 / 25^{\circ} \mathrm{C}$, where only $\mathbf{2 . 0 \%}$ of seeds germinated. Germination in complete darkness ranged from $39.5 \%$ to $\mathbf{8 0 . 5 \%}$ for chinese privet and glossy privet among temperatures, with the exception of glossy privet at $35 / 25{ }^{\circ} \mathrm{C}$, where only $0.5 \%$ of seeds germinated.

A $\mathrm{s}$ the fastest growing segment of agriculture in the United States, ornamental horticulture has been recognized as the main source of plant invasions worldwide (Dehnen-Schmutz et al., 2007). Florida is the second largest producer of ornamental plants in the United States with total industry sales in 2005 estimated at $\$ 15.2$ billion (Hodges and Haydu, 2006). While the majority of introduced plants do not escape cultivation, some plants become exceptionally adaptable, regenerate prolifically, and eventually invade natural areas (Parker et al., 2007; Reichard and

Authors gratefully acknowledge financial support from the Florida Fish and Wildlife Conservation Commission

We extend gratitude to Patricia Frey and Katelyn Stassi for providing field and technical assistance throughout the study.

${ }^{1}$ Department of Environmental Horticulture, University of Florida, Institute of Food and Agricultural Sciences (IFAS), Gainesville, FL 32611

${ }^{2}$ Indian River Research and Education Center, 2199 South Rock Road, Fort Pierce, FL 34945

${ }^{3}$ North Florida Research and Education Center, 155 Research Road, Quincy, FL 32351

${ }^{4}$ Corresponding author. E-mail: sbwilson@ufl.edu.
Hamilton, 1997; Williamson and Fitter, 1996). The probability of plants becoming naturalized increases significantly with the number of years the plants were marketed (Pemberton and Liu, 2009). Over 11 different species and hybrids from the privet genus, Ligustrum, are commercially available in the United States, each with numerous cultivars. Popularity is attributed to evergreen leaves, white-panicled flowers, adaptability to a range of landscape conditions, tolerance to pruning, resistance to disease, and wide availability (Dirr, 1998).

\section{Chinese privet}

This evergreen to semievergreen shrub or small tree native to China was introduced to the southern United States as an ornamental in 1852. The wild-type form (green) was noted as naturalized as early as 1933 forming dense thickets with seed dispersal by birds. It has since been cultivated and selected for variegation patterns, arching branch habit, and compact growth (Dirr, 1998). As a popular landscape plant, the total economic output impact of chinese privet in commercial production is estimated at $\$ 1.6$ million in Florida (Wirth et al., 2004). Although the variegated cultivars produce significantly less fruit than the wild type, they can revert to the green form over time (Dirr, 1998; Langeland et al., 2008).

Today, chinese privet has escaped cultivation globally, with 16 countries listing it as naturalized (U.S. Forest Service, 2013). In the United States, it has escaped in 20 states with a range from Rhode Island south to Florida and west to Texas [U.S. Department of Agriculture (USDA), 2013]. In Florida, herbarium vouchers document its escape in 22 counties (Wunderlin and Hansen, 2008). Florida's Exotic Pest Plant Council (FLEPPC) designates chinese privet as a Category I invasive, indicating it is altering plant communities by displacing native species, or changing ecosystem functions (FLEPPC, 2011). The University of Florida (UF) Institute of Food and Agricultural Sciences (IFAS) Assessment of Non-Native Plants in Florida's Natural Areas does not recommend chinese privet for use in northern and central Florida, with results concluding it is invasive (IFAS Invasive Plant Working Group, 2013). Because of the alarming widespread threat of chinese privet, a number of studies have investigated its control (Brown and Pezeshki, 2000; Harrington and Miller, 2005), range and rate of potential expansion (Drake et al., 2003; Merriam, 2003), tolerance to different environmental conditions including light, flooding, and carbon dioxide (Brown and Pezeshki, 2000;

\begin{tabular}{llll}
\hline $\begin{array}{l}\text { Units } \\
\text { To convert U.S. to SI, } \\
\text { multiply by }\end{array}$ & U.S. unit & SI unit & $\begin{array}{l}\text { To convert SI to U.S., } \\
\text { multiply by }\end{array}$ \\
\hline 29.5735 & $\mathrm{fl} \mathrm{oz}$ & $\mathrm{mL}$ & 0.0338 \\
0.3048 & $\mathrm{ft}$ & $\mathrm{m}$ & 3.2808 \\
3.7854 & gal & $\mathrm{L}$ & 0.2642 \\
2.54 & inch $(\mathrm{es})$ & $\mathrm{cm}$ & 0.3937 \\
28.3495 & $\mathrm{Oz}$ & $\mathrm{g}$ & 0.0353 \\
$\left({ }^{\circ} \mathrm{F}-32\right) \div 1.8$ & ${ }^{\circ} \mathrm{F}$ & ${ }^{\circ} \mathrm{C}$ & $\left({ }^{\circ} \mathrm{C} \times 1.8\right)+32$
\end{tabular}


Smith et al., 2008; Swarbrick et al., 1999; Zhang et al., 2002), competitive advantage over natives (Green and Blossey, 2012; Morris et al., 2002), and seed bank survival and germination (Burrows and Kohen, 1986; Panetta, 2000). Panetta (2000) reported that its seed bank is relatively transient and germination is not highly dependent on the liberation of seeds from their fruit.

\section{Glossy privet}

Glossy privet is an evergreen small tree with larger leaves and larger flower and fruit panicles than chinese privet. It has not been cultivated as extensively as chinese and japanese privet, but known cultivars exist. Glossy privet is often confused with japanese privet but can be distinguished by its larger size, looser habit, and translucent rim around the leaf margins (Dirr, 1998). Introduced to the United States from China, Korea, and Japan in 1794, glossy privet has since escaped cultivation in 10 states with a range north to Maryland and west to California (USDA, 2013). In Florida, herbarium vouchers document its escape in 11 counties (Wunderlin and Hansen, 2008). The FLEPPC designates glossy privet as Category I invasive (FLEPPC, 2011). The UF-IFAS Assessment of Non-Native Plants in Florida's Natural Areas cautiously approves the use of glossy privet if managed to prevent further escape (IFAS Invasive Plant Working Group, 2013). Glossy privet is a serious environmental weed in Australia (Panetta, 2000) and New Zealand (Miller and Henzell, 2000).

\section{Japanese privet}

Introduced to the United States from Japan and Korea in 1845, japanese privet is a large evergreen shrub with dense, dark green lustrous leaves and an upright habit. It typically flowers several weeks earlier than glossy privet and is more cold hardy (Dirr, 1998). Similar to chinese and glossy privet, its panicled white flowers are followed by prolific fruit in the fall that is spread by birds. Since its introduction, japanese privet has escaped cultivation in 11 southeastern states including Florida (USDA, 2013). In Florida, herbarium vouchers document its escape in only a single county (Wunderlin and Hansen, 2008), and it is not listed by FLEPPC as invasive (FLEPPC,
2011). The UF-IFAS Assessment of Non-Native Plants in Florida's Natural Areas concluded that japanese privet is not a problem species and can therefore be recommended for planting. These results, however, were footnoted to emphasize that there was insufficient evidence to fully validate the conclusion and that the status should be reassessed in 10 years (IFAS Invasive Plant Working Group, 2013). Over 16 cultivars of japanese privet have been selected for variegation, cold hardiness, leaf structure, compaction, and growth habit.

The overall objective of this study was to evaluate horticultural attributes and fruiting of three privet wild-type species and their cultivars planted in northern Florida (Quincy, USDA Plant Hardiness Zone 8 b) and southern Florida (Fort Pierce, USDA Plant Hardiness Zone 9b) (USDA, 2012). Specific objectives include: 1) assessment of plant performance and growth among cultivars; 2 ) determination of fruiting, seed production, viability, and germination among species; and 3 ) observational variegation stability.

\section{Materials and methods}

Plant material and Field CONDITIONS. Twelve chinese privet, glossy privet, or japanese privet selections were selected for this study based on availability and landscape industry use (Table 1). Chinese privet, glossy privet, and japanese privet were propagated from seed and finished in 1-gal containers at the Indian River Research and Education Center (Fort Pierce, FL). All cultivars were obtained as finished 1-gal plants from commercial nurseries (Table 1). Before planting, beds (formed north to south) were prepared by applying an herbicide formulation (for existing vegetation and nutsedge removal) and slightly disking before covering with black semipermeable landscape fabric. On 9 July 2008, nine uniform plants of each selection were spaced $7 \mathrm{ft}$ on center under full sun conditions in two locations: southern Florida (Fort Pierce) and northern Florida (Quincy). Plants were subirrigated by filling canals (southern Florida) or drip irrigated (northern Florida) as needed (generally three times per week in spring and fall and one time per week in summer). Plants were fertilized at week 9, 36, and 60 with $0.9 \mathrm{oz}$ of $15 \mathrm{~N}-3.9 \mathrm{P}-10 \mathrm{~K}$ controlled-release fertilizer (Osmocote Plus; Scotts, Marysville, $\mathrm{OH}$ ) in the area 6-12 inches from the crown. Plants were fertilized again at week 98 and 124 with an additional 2.2 and $3.0 \mathrm{oz}$ of fertilizer, respectively. Daily rainfall, temperature, and relative humidity were recorded by Florida Automated Weather Network monitoring stations located at each site (Fig. 1). Soil samples were collected from each site (collected from various locations in each plot) and analyzed by UF Analytical Service Laboratories, Gainesville, FL. Field conditions for southern Florida were as follows: Ankona sand with $0.8 \%$ organic matter, $\mathrm{pH} 6.8$, average monthly rainfall $9.8 \mathrm{~cm}$, mean minimum and maximum temperatures 9.0 and $32.2{ }^{\circ} \mathrm{C}$, respectively, and $79.1 \%$ relative humidity. Field conditions for northern Florida were as follows: Carnegie loamy fine sand with $2.6 \%$ organic matter, $\mathrm{pH} 4.7$, average monthly rainfall $12.3 \mathrm{~cm}$, mean minimum and maximum temperatures 4.6 and $30.7{ }^{\circ} \mathrm{C}$, respectively, and $78.3 \%$ relative humidity.

VISUAL QUALITY, FLOWERING, AND PLANT GROWTH. Visual quality (plant color and form) was assessed every 12 weeks for each cultivar independently at each location. Assessments of foliage color and form were performed for each plant by one or two consistent evaluators on a scale from 1 to 5 where 1 = very poor quality, not acceptable, severe leaf necrosis or chlorosis, not marketable; 2 = poor quality, not acceptable or marginally acceptable, large areas of necrosis or chlorosis, poor form; 3 = fair quality, acceptable, somewhat desirable form and color, little to no chlorosis or necrosis; 4 = good quality, very acceptable and desirable color and form without chlorosis; and $5=$ excellent quality, perfect condition, premium color and form, very marketable.

Observations of flower initiation, flowering period, and fruit formation were recorded every 4 weeks. Before fruit maturity, mesh bags were placed over panicles to prevent predation or fruit drop. Mature fruit was manually collected and counted at the end of each growing season at each location in late January to early February (weeks 84 and 132). Growth data were recorded for each plant at both sites at the beginning and end of the experiment. Growth indices were calculated as an average of the measured 


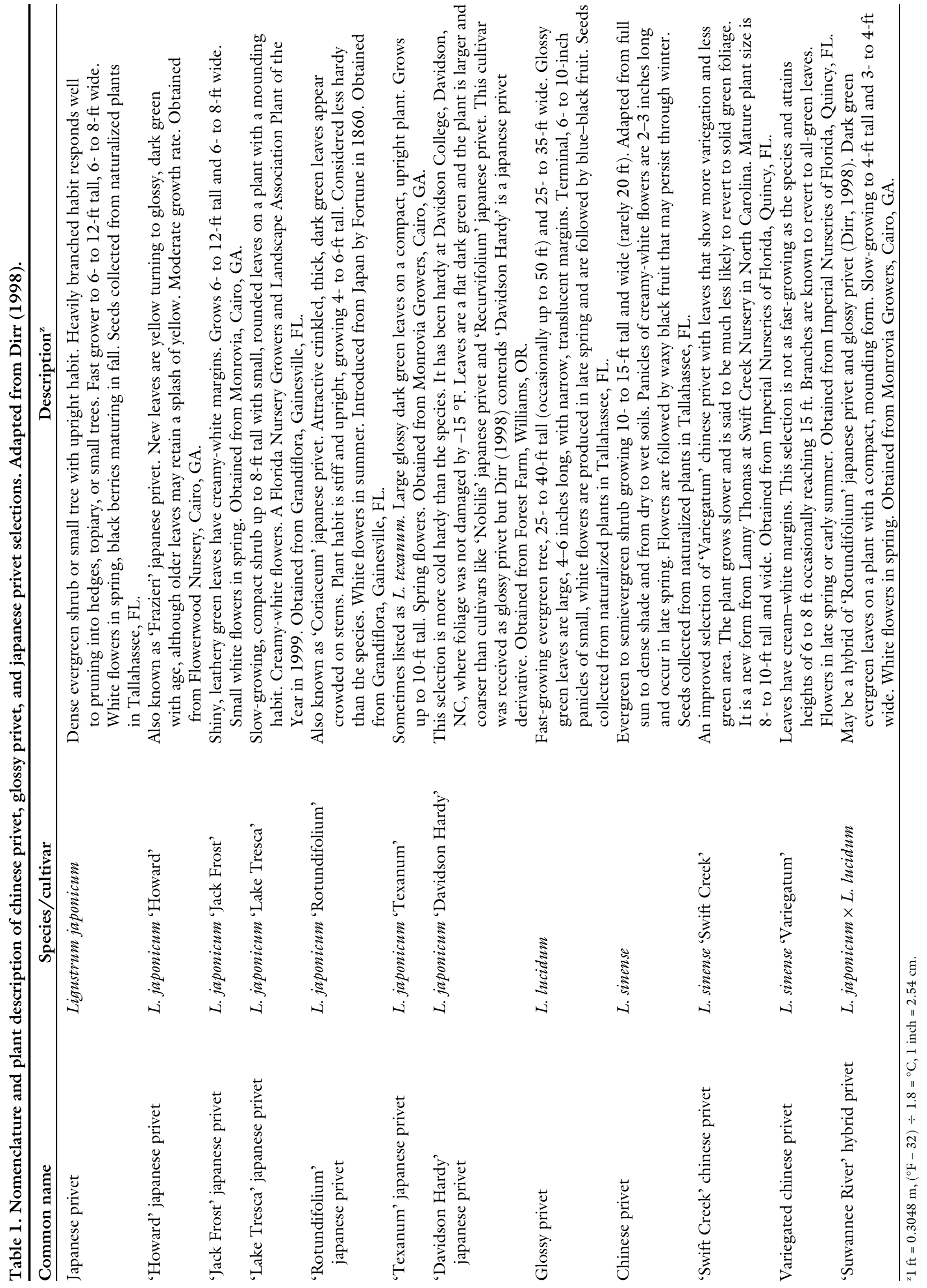



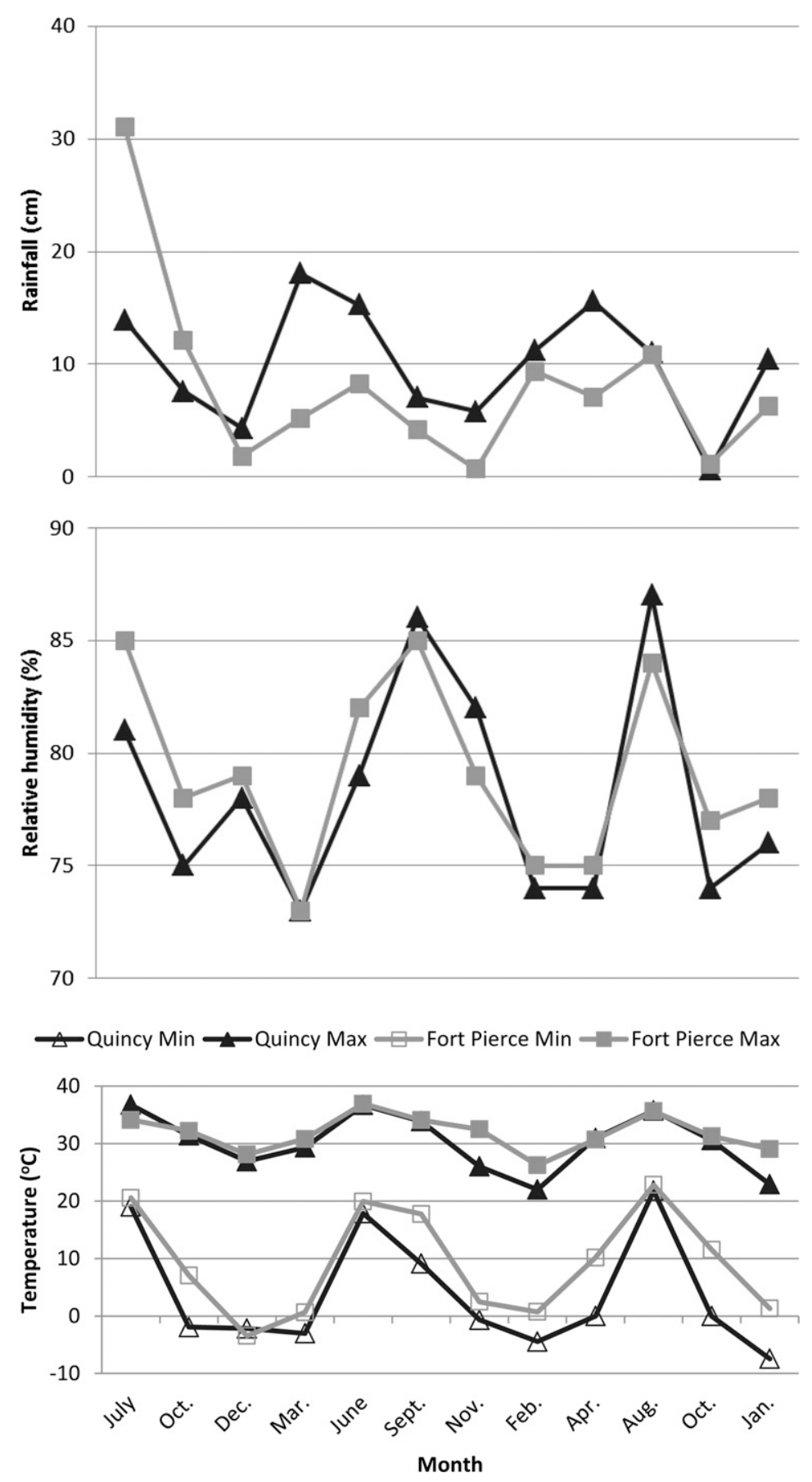

Fig. 1. Monthly average total rainfall, relative humidity, and average minimum (min) and maximum (max) temperatures from planting date (July 2008) to last evaluation date (Jan. 2011) for plants grown in northern Florida (Quincy $-\triangle$ ) and southern Florida (Fort Pierce $-\square-) ;\left(1.8 \times{ }^{\circ} \mathrm{C}\right)+32={ }^{\circ} \mathrm{F}, 1 \mathrm{~cm}=0.3937$ inch.

height (measured from crown to natural break in foliage) and two perpendicular widths $[($ width $1+$ width 2$) \div$ $2]$. Growth index rates were calculated by subtracting the initial growth index from the final growth index.

SEED GERMINATION AND VIABILITY. Mature fruit were removed from plants in mesh bags and depulped by hand using a dehulling trough
(Hoffman Manufacturing, Albany, OR). Immature seeds or seeds with visible indication of pathogen or insect damage were discarded. Cleaned seeds were gravity air dried at $22^{\circ} \mathrm{C}$ for 48-72 h before analysis. In accordance with the Tetrazolium Testing Handbook, Contribution No.29 Association of Official Seed Analysts rules (Peters, 2000), viability tests were replicated twice on a subset of 100 seeds per species from fresh seed collected in northern Florida. Seeds were pretreated by allowing them to imbibe by soaking in water overnight for $18 \mathrm{~h}$ at room temperature. Seeds were then cut longitudinally through the endosperm and stained for $18 \mathrm{~h}$ at $30-35{ }^{\circ} \mathrm{C}$ in $1.0 \%$ tetrazolium solution with positive staining patterns confirming seed viability (Mid-West Seed Service, Brookings, SD). The remaining seeds from the same populations and collection times were concurrently germinated under controlled light and temperature conditions at the Indian River Research and Education seed biology laboratory. Seeds were first treated with $0.6 \%$ sodium hypochlorite for $5 \mathrm{~min}$, rinsed three times with deionized water, and soaked overnight in aerated water. Floating or abnormal seeds were discarded. Individual treatments consisted of four replications of 50 seeds at four temperatures with and without provision of light for $60 \mathrm{~d}$. Seeds were placed in $12.7 \times 13.3 \mathrm{~cm}$ transparent polystyrene germination boxes (Hoffman Manufacturing) containing two sheets of germination paper (Anchor Paper Co., St. Paul, MN) moistened with $15 \mathrm{~mL}$ deionized water. Germination boxes were placed in temperature and light controlled chambers equipped with cool-white fluorescent lamps (model 818; Precision Scientific, Winchester, VA). Germination boxes were placed in $20 / 10$, $25 / 15,30 / 20$, and $35 / 25^{\circ} \mathrm{C}$ (day/ night). The 12 -h photoperiod was administered by providing 12 -h light at $20,25,30$, or $35^{\circ} \mathrm{C}$ photosynthetic photon flux was $22-30 \mu \mathrm{mol} \cdot \mathrm{m}^{-2} \cdot \mathrm{s}^{-1}$ at shelf level) followed by 12 -h dark at $10,15,20$, or $25^{\circ} \mathrm{C}$, respectively. The dark treatment was provided by wrapping germination boxes with two layers of heavy-duty aluminum foil. There were insufficient seeds (from the same population) available to administer the dark treatment for japanese privet. Germination of seed receiving the $12-\mathrm{h}$ photoperiod was recorded every other day for $60 \mathrm{~d}$ and an additional 5 to $10 \mathrm{~mL}$ of deionized water was added to germination boxes as needed. A seed was considered germinated when radicle emergence was $\geq 2.0 \mathrm{~mm}$. Seeds in the dark treatment remained unopened throughout the experiment. At the end of the germination period, final germination 
percentage (FGP) and days to $50 \%$ of FGP (T50) was determined per germination box.

EXPERIMENTAL DESIGN AND Statistical analysis. The field experiments were conducted similarly in northern and southern Florida. A randomized complete block experimental design was used with 12 privet selections placed in three-plant plots replicated three times (blocks). Visual quality was assessed every 12 weeks on each plant at both sites. Growth data were collected on each plant, subjected to analysis of variance (ANOVA) using SAS statistical software (version 9.2 for Windows; SAS Institute, Cary, NC), and significant means separated by least significant difference at $P=0.05$. Percentage data for the seed viability and germination studies were transformed by square root arcsine before conducting an ANOVA. For the germination study, a split block experimental design was used with temperature as the main block and species as the splitplot. Transformed means were separated by a Duncan's multiple range test $(P=0.05)$. Untransformed cultivar means are presented in Table 2.

\section{Results and discussion}

Visual quality and growth varied by cultivar and site (Fig. 2, Table 3 ). In northern Florida, 'Lake Tresca' and 'Rotundifolium' japanese privet had the lowest growth rate index, whereas, glossy privet and chinese privet had the greatest growth rate index, as compared with other cultivars
(Table 3). In southern Florida, 'Lake Tresca', 'Rotundifolium', and 'Suwannee River' privet had similarly low growth rates, whereas chinese privet and glossy privet had the greatest growth rates (Table 3 ). Regardless of cultivar, monthly visual quality of plants typically differed between sites (Fig. 2); however, cumulative averages (weeks 0 to 132) were overall similar (Table 3 ) with two exceptions. In northern Florida, japanese privet and 'Lake Tresca' japanese privet received average visual quality ratings (2.81 and 2.73 , respectively) significantly lower than the other cultivars. In southern Florida, 'Swift Creek' chinese privet received the lowest average visual quality (2.32). 'Davidson Hardy' japanese privet performed similarly in northern and southern Florida during the first year, but then declined in southern Florida for the remainder of the study (Fig. 2). Each site experienced varying patterns of rainfall and minimal and maximal average temperatures, which likely influenced growth, visual quality, and fruit set (Fig. 1).

Flowering was typically observed in May for all cultivars followed by fruit initiation in June/July, with maturity in January. After 132 weeks, northern Florida plants produced over 600 times more fruit than southern Florida plants (Table 4). Of interest to note is that both variegated chinese privet cultivars (Swift Creek and Variegatum) fruited, but far less than the green wild-type form. Fruiting of variegated chinese privet cultivars also occurred later than the green wildtype form. As early as 72 weeks, the variegated chinese privet already showed some reversion to the invasive green form. Although quantifying fruit production on green reverted branches compared with variegated branches was not possible within the timeframe of this study, fruit production on green reverted branches of chinese privet has been observed to be heavier than on variegated branches of the same plant (J. Aldrich, unpublished data). The variegated japanese privet cultivars did not show any reversion during the 132-week study.

Pregermination viability performed on a subsample of seeds showed significant difference among species with glossy privet having the greatest seed viability $(91.8 \%)$ followed by chinese privet $(81.0 \%)$, followed by japanese privet $(57.3 \%)$. Lower viability of japanese privet could be associated with the presence of ligustrum weevil (Ochyromera ligustri). For germination, there was a significant interaction between temperature and species. At $20 / 10,25 / 15$, and $30 / 10^{\circ} \mathrm{C}$ with a $12-\mathrm{h}$ photoperiod, germination was not significantly different among species (ranging between $51 \%$ and $78.5 \%$ ). At $35 / 25{ }^{\circ} \mathrm{C}$, chinese privet had the highest germination $(72.5 \%)$ followed by japanese privet $(54 \%)$, followed by glossy privet $(2.0 \%)(P<0.0001)$. Seeds did not require light to germinate; however, germination in the dark was lower for glossy privet at $30 / 20$ and $35 / 25^{\circ} \mathrm{C}$ as compared with chinese privet (Table 2 ).

Table 2. Germination percentage and number of days to $50 \%$ of final germination (T50) of seed collected from resident populations of chinese privet, glossy privet, and japanese privet in northern Florida. Seeds were germinated with or without light (12-h photoperiod) in germination boxes placed in growth chambers set at $20 / 10,25 / 15,30 / 20$, and $35 / 25{ }^{\circ} \mathrm{C}$ for $60 \mathrm{~d}$. A subset of the same seed population was concurrently (and destructively) tested for pregermination viability.

\begin{tabular}{|c|c|c|c|c|c|c|c|c|c|}
\hline \multirow[b]{3}{*}{ Cultivar/species } & \multicolumn{4}{|c|}{ Germination-12-h light $(\%)^{\mathrm{z}}$} & \multicolumn{4}{|c|}{$\mathrm{T} 50(\mathrm{~d})$} & \multirow[b]{3}{*}{ Viability (\%) } \\
\hline & \multicolumn{4}{|c|}{ Temp $\left({ }^{\circ} \mathbf{C}\right)^{y}$} & \multicolumn{4}{|c|}{$\operatorname{Temp}\left({ }^{\circ} \mathrm{C}\right)$} & \\
\hline & $20 / 10$ & $25 / 15$ & $30 / 20$ & $35 / 25$ & $20 / 10$ & $25 / 15$ & $30 / 20$ & $35 / 25$ & \\
\hline Glossy privet & $75.5 \mathrm{a}$ & $70.5 \mathrm{a}$ & $51.0 \mathrm{a}$ & $2.0 \mathrm{c}$ & $23.0 \mathrm{~b}$ & $21.3 \mathrm{a}$ & $34.0 \mathrm{a}$ & - & $91.8 \mathrm{a}$ \\
\hline Japanese privet & $\begin{array}{c}68.0 \mathrm{a} \\
* * \mathrm{w}\end{array}$ & $71.0 \mathrm{a}$ & $61.0 \mathrm{a}$ & $54.0 \mathrm{~b}$ & $\begin{array}{c}27.3 \mathrm{a} \\
* *\end{array}$ & $17.8 \mathrm{~b}$ & $18.3 \mathrm{~b}$ & $29.5 \mathrm{a}$ & $57.3 \mathrm{c}$ \\
\hline
\end{tabular}

Temp $\times$ species

$* * \mathrm{w}$

Germination-24-h dark (\%)

$\begin{array}{llllr}\text { Chinese privet } & 73.0 \mathrm{a} & 76.0 \mathrm{a} & 67.5 \mathrm{a} & 63.5 \mathrm{a} \\ \text { Glossy privet } & 80.5 \mathrm{a} & 72.5 \mathrm{a} & 39.5 \mathrm{~b} & 0.5 \mathrm{~b}\end{array}$

Temp $\times$ species

**

${ }^{2}$ Mean separation was conducted by Duncan's multiple range test on transformed means.

$\mathrm{y}\left(1.8 \times{ }^{\circ} \mathrm{C}\right)+32={ }^{\circ} \mathrm{F}$.

'Different lowercase letters within columns are significantly different at $P=0.05$.

"Indicates significant interaction between temperature and species. 


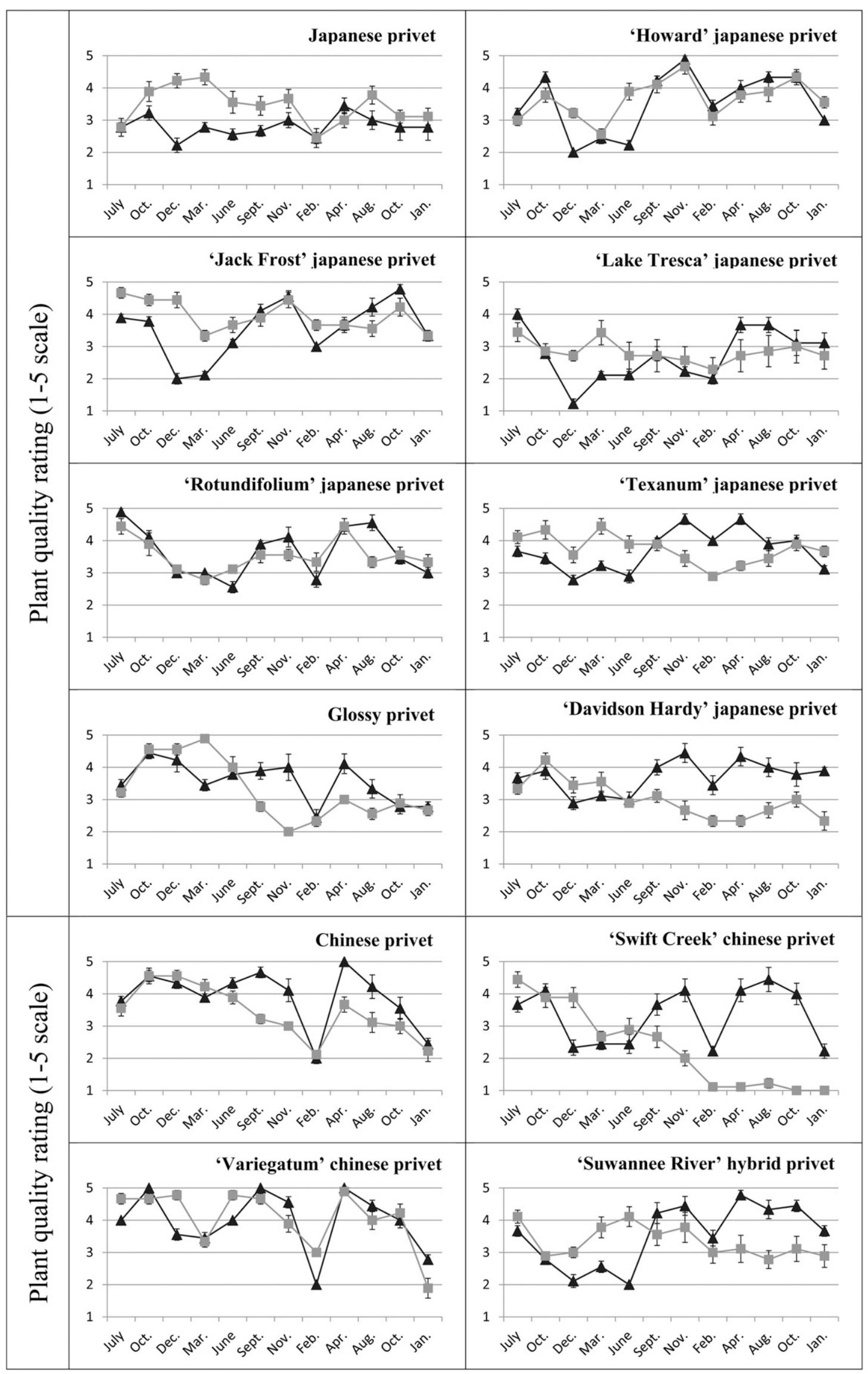

Fig. 2. Visual quality performance ratings of chinese privet, glossy privet, and japanese privet selections grown for 132 weeks in northern Florida (Quincy -- ) and southern Florida (Fort Pierce $-\square-$ ). Visual quality was rated 1 (very poor) to 5 (excellent).

Horflechnology $\cdot$ February 2014 24(1)

153 
Table 3. Growth index rate and average visual quality rating (based on color and plant form) of chinese privet, glossy privet, and japanese privet selections grown for 132 weeks in northern Florida (Quincy) and southern Florida (Fort Pierce).

\begin{tabular}{lccccc}
\hline & \multicolumn{2}{c}{$\begin{array}{c}\text { Growth index } \\
\text { rate }(\mathbf{c m})^{\mathbf{z}}\end{array}$} & & \multicolumn{2}{c}{$\begin{array}{c}\text { Avg visual quality } \\
(\mathbf{1 - 5} \text { scale) }\end{array}$} \\
\cline { 2 - 3 } \cline { 5 - 6 } Cultivar/species & Quincy & Fort Pierce & & Quincy & Fort Pierce \\
\hline Chinese privet & 294.2 & 152.6 & & 3.91 & 3.42 \\
'Swift Creek' chinese privet & 130.8 & $-{ }^{\mathrm{x}}$ & & 3.31 & 2.32 \\
'Variegatum' chinese privet & 215.6 & 67.8 & & 3.98 & 4.06 \\
Glossy privet & 270.5 & 130.4 & & 3.55 & 3.29 \\
Japanese privet & 159.3 & 111.3 & & 2.81 & 3.44 \\
'Howard' japanese privet & 173.8 & 93.0 & & 3.54 & 3.66 \\
'Jack Frost' japanese privet & 148.9 & 88.2 & & 3.55 & 3.95 \\
'Lake Tresca' japanese privet & 37.4 & 45.6 & & 2.73 & 2.96 \\
'Rotundifolium' japanese privet & 30.0 & 20.4 & & 3.65 & 3.54 \\
'Texanum' japanese privet & 187.4 & 129.3 & & 3.70 & 3.73 \\
'Davidson' japanese privet & 193.3 & 111.3 & & 3.70 & 2.99 \\
'Suwannee River' hybrid privet & 96.8 & 38.8 & & 3.54 & 3.34 \\
LSD (0.05) & 29.5 & 22.7 & & 0.5 & 0.6 \\
\hline
\end{tabular}

${ }^{\mathrm{z}}$ Growth rate index calculated by subtracting the week 0 growth index from the week 144 growth index; $1 \mathrm{~cm}=$ 0.3937 inch

Visual quality was rated 1 (poor quality) to 5 (excellent).

${ }^{x}$ Species did not survive the duration of the experiment at this location.

weast significant difference at $P=0.05$.

Table 4. Average fruit per plant counted for chinese privet, glossy privet, and japanese privet selections grown in northern Florida (Quincy) and southern Florida (Fort Pierce) from week 84 through week 132.

\begin{tabular}{lrc}
\hline & \multicolumn{2}{c}{ Avg fruit (no.) } \\
\cline { 2 - 3 } Common name & Quincy & Fort Pierce \\
\hline Chinese privet & 49,692 & 158 \\
'Swift Creek' chinese privet & 92 & 0 \\
'Variegatum' chinese privet & 8,957 & 2 \\
Glossy privet & 8,606 & 0 \\
Japanese privet & 3,207 & 0.33 \\
'Howard' japanese privet & 10,931 & 2 \\
'Jack Frost' japanese privet & 3,624 & 0 \\
'Lake Tresca' japanese privet & 125 & 21 \\
'Rotundifolium' japanese privet & 2 & 0 \\
'Texanum' japanese privet & 28,071 & 11 \\
'Davidson' japanese privet & 5,276 & 0.44 \\
'Suwannee River' hybrid privet & 153 & 0 \\
\hline
\end{tabular}

Efficient resource use, rapid growth rates, and reproductive success have all been associated with invasiveness (Wilson et al., 2010). Early and generous seed production, lack of dormancy, germination over a wide range of conditions, long-distance dispersal mechanisms, and long-lived seed banks are often characteristics of successful invaders (Pyšek and Richardson, 2007). Panetta (2000) studied the fates of fruits and seeds of glossy privet and chinese privet maintained under natural rainfall conditions. They found that germination of these species was not highly dependent on the liberation of seeds from the pericarp and that seed banks are relatively transient, in that most propagules survive for less than 12 months. Interestingly, soil moisture levels influenced the success of germination when seeds were surface sown or shallowly buried. This suggests that frugivores may function more as dispersers rather than as germination mediators and that preventing initial propagule pressure is critical to land management.

In addition to the effect of rainfall, planting depth, and pericarp removal on the spread of chinese privet, light intensity is also a factor. Morris et al. (2002) examined plants growing in sunny conditions along the wooded edges of red cedar (Juniperus virginia) glades and shade conditions in the understory of a red cedar woodland complex in Tennessee. They found that plants growing along the wooded edges of cedar glades produced 3.75 times more fruit per ramet than those growing in the understory woodland complex. This study was conducted in full sun, fieldtrial conditions that may be less typical of a home landscape. Nevertheless, temperature dramatically affected fruit formation among the two Florida sites (northern Florida has more chilling hours throughout the winter), yet seeds could germinate under a wide range of diurnal conditions. In an earlier experiment under constant temperatures without light $(5,10,15,20,25$, and $30{ }^{\circ} \mathrm{C}$ ), Burrows and Kohen (1983) reported greatest germination of chinese privet occurred at 15,20 , or $25{ }^{\circ} \mathrm{C}$ while greatest germination of glossy privet occurred at 10 or $15^{\circ} \mathrm{C}$. Although fruit production was significantly less in the privet cultivars trialed, Knight et al. (2011) argue that, regardless of species, reducing fecundity in new cultivars may be inadequate to reduce population growth, unless it is demonstrated that cultivars 1 ) do not revert to "wild type" or more weedy forms by reversion, 2) are true to type, and 3 ) cannot hybridize with closely related wild-type forms.

Advances in breeding technologies to introduce new and novel cultivars have increased significantly during the last decade (Drew et al., 2010). Recent breeding initiatives have included sterility for new cultivar releases of wild-type species that have invasive potential (Czarnecki et al., 2012; Freyre et al., 2012; Knight et al., 2011; Ranney, 2004). Results from this research will conceivably guide the horticulture industry, research breeding efforts, land managers and consumer awareness for plant selection, population prevention, and control.

\section{Literature cited}

Brown, C.E. and S.R. Pezeshki. 2000. A study on waterlogging as a potential tool to control Ligustrum sinense populations in western Tennessee. Wetlands 20:429437.

Burrows, F.J. and J. Kohen. 1983. Germination of Ligustrum lucidum W.T. Ait. and $L$. sinense Lour. at different temperatures. Austral. J. Weeds 2(4): $130-132$. 
Burrows, F.J. and J. Kohen. 1986. Inhibition of germination in privet. Plant Prot. Q. 1:107-108.

Czarnecki, D.M., S.B. Wilson, G.W. Knox, R. Freyre, and Z. Deng. 2012. UF-T3 and UF-T4: Two sterile Lantana camara cultivars. HortScience 47:132137.

Dehnen-Schmutz, K., J. Touza, C. Perrings, and M. Williamson. 2007. A century of the ornamental plant trade and its impact on invasion success. Divers. Distrib. 13:527534.

Dirr, M.A. 1998. Manual of woody landscape plants. Their identification, ornamental characteristics, culture, propagation and uses. 5th ed. Stipes Publ., Champaign, IL.

Drake, S.J., J.F. Weltzin, and P.D. Parr. 2003. Assessment of non-native invasive plant species on the United States Department of Energy Oak Ridge National Environmental Research Park. Castanea 68:15-30.

Drew, J., N. Anderson, and D. Andow. 2010. Conundrums of a complex vector for invasive species control: A detailed examination of the horticultural industry. Biol. Invasions 12:2837-2851.

Florida Exotic Pest Plant Council. 2011. Florida EPPC's 2011 invasive plant species list. 1 Oct. 2013. <http://www.fleppc. org/list/11list.html>.

Freyre, R., A. Moseley, S.B. Wilson, and G.W. Knox. 2012. Fruitless Ruellia simplex R10-102 ('Mayan Purple') and R10108 ('Mayan White'). HortScience 47:1808-1814.

Green, B.T. and B. Blossey. 2012. Lost in the weeds: Ligustrum sinense reduces native plant growth and survival. Biol. Invasions 14:139-150.

Harrington, T.B. and J.H. Miller. 2005. Effects of application rate, timing, and formulation of glyphosate and triclopyr on control of chinese privet (Ligustrum sinense). Weed Technol. 19:47-54.

Hodges, A.W. and J.J. Haydu. 2006. Economic impacts of the Florida environmental horticulture industry in 2005. Univ. Florida Food Resource Econ. Rpt. FE675. 12 Oct. 2013. <http:// economicimpact.ifas.ufl.edu>.
Institute of Food and Agricultural Sciences Invasive Plant Working Group. 2013. IFAS assessment of non-native plants in Florida's natural areas. 1 Oct. 2013. <http://plants.ifas.ufl.edu/ assessment/conclusions.html>.

Knight, T.M., K. Havens, and P. Vitt. 2011. Will the use of less fecund cultivars reduce the invasiveness of perennial plants? Bioscience 61:816-822.

Langeland, K.A., H.M. Cherry, C.M. McCormick, and K.A. Craddock Burks. 2008. Identification and biology of nonnative plants in Florida's natural areas. 2nd ed. Univ. Florida, Inst. Food Agr. Sci. Commun. Serv., Gainesville, FL.

Merriam, R.W. 2003. The abundance, distribution and edge associations of six non-indigenous, harmful plants across North Carolina. J. Torrey Bot. Soc. 130: 283-291.

Miller, S.A. and R.F. Henzell. 2000. Seed germination of weeds from New Zealand native plant communities. Agron. Soc. N.Z. 12:115-116.

Morris, L.L., J.L. Walck, and S.N. Hidayati. 2002. Growth and reproduction of the invasive Ligustrum sinense and native Forestiera ligustrina (Oleaceae): Implications for the invasion and persistence of a nonnative shrub. Intl. J. Plant Sci. 163:1001-1010.

Panetta, F.D. 2000. Fates of fruits and seeds of Ligustrum lucidum W.T. Ait. and L. sinense Lour. maintained under natural rainfall or irrigation. Austral. J. Bot. 48:701-705.

Parker, C., B.P. Caton, and L. Fowler. 2007. Ranking nonindigenous weed species by their potential to invade the United States. Weed Sci. 55:386-397.

Pemberton, R.W. and H. Liu. 2009. Marketing time predicts naturalization of horticultural plants. Ecology 90:69-80.

Peters, J. 2000. Tetrazolium testing handbook. Contribution no. 29 to the handbook on seed testing. Assn. Official Seed Analysts, Las Cruces, NM.

Pyšek, P. and D.M. Richardson. 2007. Traits associated with invasiveness in alien plants: Where do we stand? Ecological Studies, p. 97-193. In: W. Nentwig (ed.). Biological invasions. Springer-Verlag, Berlin/Heidelberg, Germany.

Ranney, T.G. 2004. Population control: Developing non-invasive nursery crops. Comb. Proc. Intl. Plant Propagator's Soc. 54:604-607.

Reichard, S.H. and C.W. Hamilton. 1997. Predicting invasions of woody plants introduced into North America. Conserv. Biol. 11:193-203.

Smith, K.E., G.B. Runion, and S.A. Prior. 2008. Chinese privet (Ligustrum sinense) in an elevated $\mathrm{CO}_{2}$ environment. Bot. Res. J. I(2):43-48.

Swarbrick, J.T., S.M. Timmins, and K.M. Bullen. 1999. The biology of Australian weeds. Ligustrum lucidum Aiton and Ligustrum sinense Lour. Plant Prot. Q. 14:122-130.

U. S. Department of Agriculture. 2012. About the USDA hardiness zones. 25 May 2013. <http://plants.usda.gov/ hardiness.html>.

U.S. Department of Agriculture. 2013. The PLANTS database. 15 May 2013. $<$ http://plants.usda.gov/core/profile? symbol=LISI $>$.

U.S. Forest Service. 2013. Pacific Island ecosystems at risk. Ligustrum sinense. 10 Oct. 2013. <http://www.hear.org/ pier/species/ligustrum_sinense.htm>.

Wilson, S.B., G.W. Knox, Z. Deng, and R. Freyre. 2010. Characterizing the invasive potential of ornamental plants. Acta Hort. 937:1183-1192.

Wirth, F.F., K.J. Davis, and S.B. Wilson. 2004. Florida nursery sales and economic impacts of 14 potentially invasive landscape plant species. J. Environ. Hort. 22:12-16.

Williamson, M.H. and A. Fitter. 1996. The characters of successful invaders. Biol. Conserv. 78:163-170

Wunderlin, R.P. and B.F. Hansen. 2008. Atlas of Florida vascular plants. 1 Oct. 2013. <http://www.plantatlas.usf.edu/>.

Zhang, S., K. Ma, and L. Chen. 2002. Tempo-spatial variations in stomatal conductance, aperture and density of Ligustrum sinense acclimated to different light environments. Acta Bot. Sin. 44:12251232 . 